\title{
Design of Normal Concrete Mixtures Using Workability-Dispersion-Cohesion Method
}

\author{
Hisham Qasrawi \\ Civil Engineering Department, The Hashemite University, Zarqa 13133, Jordan \\ Correspondence should be addressed to Hisham Qasrawi; hisham_qasrawi@yahoo.com
}

Received 4 November 2015; Accepted 4 May 2016

Academic Editor: Luigi Di Sarno

Copyright ( 2016 Hisham Qasrawi. This is an open access article distributed under the Creative Commons Attribution License, which permits unrestricted use, distribution, and reproduction in any medium, provided the original work is properly cited.

\begin{abstract}
The workability-dispersion-cohesion method is a new proposed method for the design of normal concrete mixes. The method uses special coefficients called workability-dispersion and workability-cohesion factors. These coefficients relate workability to mobility and stability of the concrete mix. The coefficients are obtained from special charts depending on mix requirements and aggregate properties. The method is practical because it covers various types of aggregates that may not be within standard specifications, different water to cement ratios, and various degrees of workability. Simple linear relationships were developed for variables encountered in the mix design and were presented in graphical forms. The method can be used in countries where the grading or fineness of the available materials is different from the common international specifications (such as ASTM or BS). Results were compared to the ACI and British methods of mix design. The method can be extended to cover all types of concrete.
\end{abstract}

\section{Introduction}

Concrete mix design is the procedure by which the proportions of constituent materials are suitably selected so as to produce concrete satisfying all the required properties for the minimum cost. Many attempts have been made to develop a reliable method for normal concrete mix design in various parts of the world ever since usage of concrete began as a structural material [1-12]. Among all available methods, the ACI 211.1 [13], the British Road Note Number 4 , and the British DoE $[14,15]$ methods of mix design are the most widely used ones in the Middle East. Many of the Middle East countries adapted one or more of these methods as the basis for their concrete mix proportioning (examples are Kuwaiti, Saudi, and Jordanian specifications [16-18]). Because of the variations of the available materials (in many countries) from the American or the British specifications, the use of the American or the British methods of mix design requires special care, individual experience, and special judgments in order to arrive at the optimum design. Therefore, adjustment of mix proportions may become slow and tedious. The most common variations of the available materials are aggregate grading, shape, fineness, and texture. These variations directly affect both the workability and the final properties of concrete [11]. According to Murdock and Brook [19], Neville [14], and El-Rayyes [10], two of the most necessary and vital conditions to attain economy in the mix design process are the use of locally available materials and the adoption of less restrictive specification requirements. Several researches have been published emphasizing the modification of available mix design methods (such as the ACI 211.1) in order to suit local materials [20-25]. In order to arrive at a better relationship between $\mathrm{w} / \mathrm{c}$ ratio and the strength, some researchers used obtained special plots for EN and BS cements [26, 27]. Therefore, the use of the ACI or BS methods would not necessarily end up with the optimum mix design. Hence, the need for a new method, which takes into account the variations in materials, becomes necessary.

In addition to the foregoing problems, another difficulty, usually experienced in site and encountered in the mix design, is the assessment of workability. Workability has been used qualitatively to describe the ease with which the concrete can be mixed, transported, placed, compacted, and finished. Thus, workability is rather difficult to define precisely, because it is intimately related, among others, to the following: (a) mobility: that property which determines how easily the concrete can flow into the moulds and around the reinforcement, (b) stability: that property which determines 


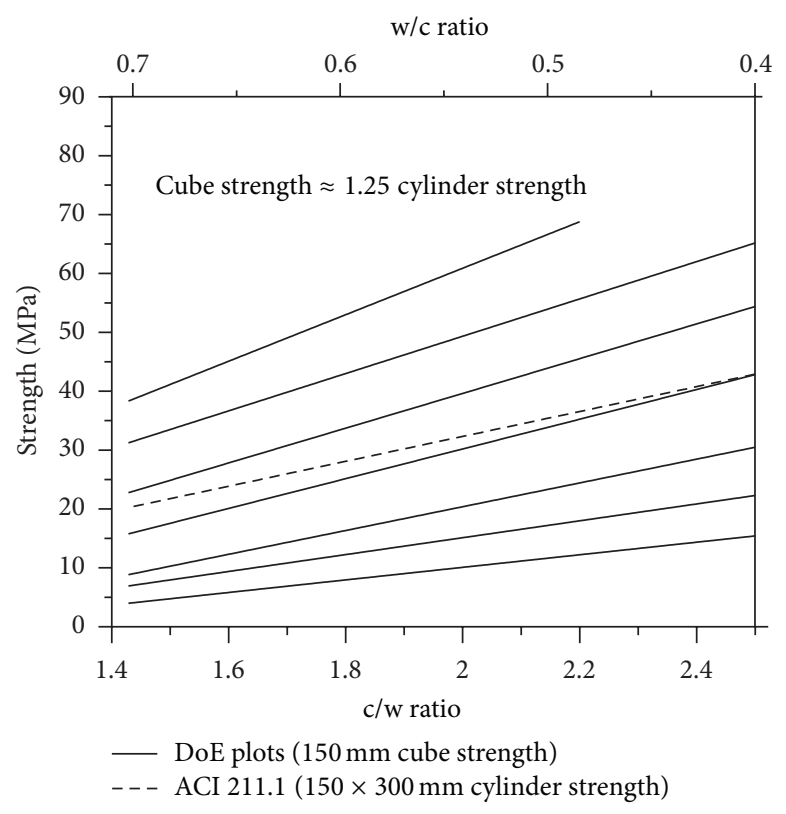

(a) DoE and ACI 211.1 plots

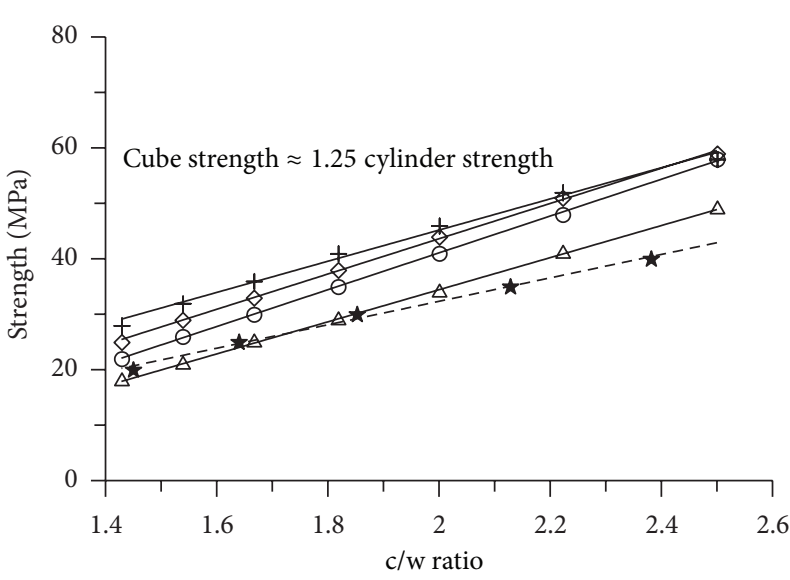

+ Upper for CEM 52.5 (150 mm cube strength)

$\diamond$ Lower for CEM 52.5 and upper for 42.5 ( $150 \mathrm{~mm}$ cube strength)

O Lower for CEM 42.5 and upper for CEM 32.5 (150 mm cube strength)

$\triangle$ Lower for CEM 32.5 ( $150 \mathrm{~mm}$ cube strength)

$\star$ ACI $211.1(150 \times 300 \mathrm{~mm}$ cylinder strength $)$

(b) CEM cements and ACI 211.1 plots

Figure 1: Relationship between the $\mathrm{c} / \mathrm{w}$ ratio and the strength of concrete (MPa).

the ability of the concrete to remain as a stable and coherent mass during concrete production, (c) compactability: that property of concrete which determines how easily concrete can be compacted to remove air voids, and (d) finishability: that property which describes the easiness to produce the specified surface $[28,29]$.

In sites, usually special experience and slump test results are used together to assess workability. Although the slump test is not sufficient to measure and describe the workability of concrete, it is the test used extensively in site work all over the world. However, its relation with other workability measures and thus its relation to the degree of workability are well established and published in the literature. Some of the references cited here describing such relations are $[8,9,13-15$, $29,30]$. Because of the problems encountered in workability measurements and assessment, the author referred (in the research) to the degree of workability rather than describing it in an absolute value. Therefore it is necessary to obtain factors which directly relate to the degree of workability and can be used in the estimation of the mix proportions. This, of course, is better than relating the mix design to some test values, which might not represent the actual degree of workability or might not be practical or cannot be used at sites.

Another problem that arises in the concrete mix design is the choice of water/cement ratio to satisfy the required properties. Since Abrams formulated the water/cement ratio law in 1918 [1], it became well known that, under ordinary conditions of exposure and using Portland cement, the water/cement ratio is mainly governed by the strength requirement [13-15]. Thus, the relationship shown in Figure 1 can be used to estimate the water/cement ratio required for certain strength. Figure 1 is a replot of the figure that appeared in the DoE mix design method [15] but cement/water ratio is plotted against compressive strength instead of the conventional water/cement ratio. The use of $c / w$ ratio instead of $\mathrm{w} / \mathrm{c}$ ratio would result in linearization of the curves, which in turn would result in better estimates of the results. The values given in the ACI 211.1 are also plotted. Again, the use of $\mathrm{c} / \mathrm{w}$ ratio results in straight line relationships. It is worth noting that the use of the DoE plots requires the determination of the compressive strength of concrete mixes made with a free cement/water ratio of 2 when local materials are used. This value can be easily obtained in any country or region using its own local materials.

From the foregoing review, it is seen how important it is to recommend a practical mix design method in which the actual properties of the locally available material and the assessment of workability are taken into consideration during the stages of mix design.

The method described in this work covers normal concrete mixes, which include those made of normal-weight aggregate, normal strength range (15 to $45 \mathrm{MPa}$, as in ACI 211.1), do not contain special materials such as fibers, have a normal degree of workability ranging from low to high (25 to $175 \mathrm{~mm}$ slump, as in ACI 211.1), always contain coarse and fine aggregate (e.g., no-fines concrete is excluded), and do not contain special admixture. In other words, any special concrete is excluded.

\section{General Principles}

The method of the mix design described in this work uses the following principles and assumptions.

(1) The principle of the absolute volume theory (ACI 211.1) is considered applicable. The theory states that the sum of the absolute volumes of all ingredients, including air voids, equals 
the volume of concrete in its final stage. In mathematical form, it is given as follows:

$$
V_{\mathrm{M}}+V_{\mathrm{CA}}+A=V_{\mathrm{CO}},
$$

where $V_{\mathrm{CO}}$ is volume of concrete in its final stage, $A$ is volume of air voids in concrete, $V_{\mathrm{CA}}$ is volume of solid particles of coarse aggregates, and $V_{\mathrm{M}}$ is volume of mortar which equals the sum of both the volume of the sand particles $\left(V_{\mathrm{S}}\right)$ and the volume of the paste $\left(V_{\mathrm{P}}\right), V_{\mathrm{M}}=V_{\mathrm{P}}+V_{\mathrm{S}}$. Moreover, the volume of the paste equals the sum of the volumes of water $\left(V_{\mathrm{W}}\right)$ and volume of the cement $\left(V_{\mathrm{C}}\right): V_{\mathrm{P}}=V_{\mathrm{C}}+V_{\mathrm{W}}$.

For a unit volume of concrete (UV $=1.0$ cubic meter or 27 cubic feet), the equation can be written as

$$
V_{\mathrm{M}}+V_{\mathrm{CA}}=\mathrm{UV}-A \text {. }
$$

(2) Before compaction, the bulk volume of mortar coats the coarse aggregate particles, fills the voids between particles, and disperses them apart. Based on this assumption, (3) can be derived and written in the form

$$
B_{1} \times V_{\mathrm{M}}=B_{1} \times\left(V_{\mathrm{P}}+V_{\mathrm{S}}\right)=B_{2} \times R \times V_{B_{\mathrm{CA}}},
$$

where $B_{1}$ is a factor relating the bulk volume of mortar to the solid volumes of mortar particles, $B_{2}$ is a factor allowing for the dispersion of coarse aggregate particles, which is basically affected by the degree of workability and the change in bulk volume before and after compaction, $V_{B_{C A}}$ is the bulk volume of dry loose coarse aggregate particles, and $R$ is the voids ratio in the loose coarse aggregates expressed in relative form.

Equation (3) can be rewritten in the form

$$
V_{\mathrm{M}}=V_{\mathrm{P}}+V_{\mathrm{S}}=\frac{B_{2}}{B_{1}} \times R \times V_{B_{\mathrm{CA}}}=\mathrm{WD} \times R \times V_{B_{\mathrm{CA}}} .
$$

The factor $\mathrm{WD}$, which is the ratio between $B_{1}$ and $B_{2}$, is called (in this work) the "workability-dispersion" factor. From the definition of the WD factor and the corresponding $B_{1}$ and $B_{2}$ factors, it can be easily drawn that the factor WD takes into consideration the properties of aggregates, which include (a) the maximum size, (b) the fineness, (c) the grading, (d) the shape and texture, (e) the specific gravity (compaction is easier with heavier particles), and (f) the degree of workability. Komar [7] suggested a factor for mix design, based on a somewhat similar principle.

In this research, the above factors are taken into consideration by measuring the voids ratio in aggregates, measuring the fineness modulus of the fine aggregate, and obtaining the grading of aggregates by a simple sieve analysis test. The factor "WD" represents the mobility-compactability principle that appears in the workability definition in the introduction.

(3) Another assumption (which takes into consideration the cement-sand matrix) states that cement particles coat the fine aggregate particles and disperse them apart but keep them cohesive and stable. Based on this assumption, (5) can be derived. In mathematical form (as done with (4)), the relationship can be reduced in its final form to

$$
\begin{aligned}
V_{\mathrm{P}} & =V_{\mathrm{W}}+V_{\mathrm{C}}=\frac{B_{\mathrm{FA} 2}}{B_{\mathrm{FA} 1}} \times R_{\mathrm{FA}} \times V_{B_{\mathrm{FA}}} \\
& =\mathrm{WC} \times R_{\mathrm{FA}} \times V_{B_{\mathrm{FA}}},
\end{aligned}
$$

where, similar to the coarse aggregate factors, $B_{\mathrm{FA} 1}, B_{\mathrm{FA} 2}$, and $R_{\mathrm{FA}}$ are factors relating to the bulk volume of fine aggregate. WC, which is the ratio between $B_{\mathrm{FA} 2}$ and $B_{\mathrm{FA} 1}$, is called the "workability-cohesion factor." $V_{B_{\mathrm{FA}}}$ is the bulk volume of dry loose fine aggregate and $R_{\mathrm{FA}}$ is the voids ratio in fine aggregate in its loose state expressed in relative form.

It can be easily drawn that the factor WC is expected to be affected by (a) the fineness of fine aggregate, expressed as fineness modulus, (b) shape, texture, and grading of fine particles which affect the voids, (c) the degree of workability, (d) the specific gravity of aggregates, and (e) the required properties of the hardened concrete such as strength, durability, and impermeability which are mainly controlled by the water/cement ratio and cement content.

The factor "WC" represents the workability-stabilitycompactability principle, which appears in the introduction.

(4) The values shown in the ACI 211.1 for volume of entrapped air in normal concrete mixes are considered applicable in the first estimates of the mix design.

(5) The strength relationships shown in Figure 1(a) are considered applicable. The figure is a reproduction of the plot provided by the DoE method using the $\mathrm{c} / \mathrm{w}$ ratio instead of the w/c ratio. Also it shows the values presented in the ACI 211.1 (SI units). A linear relationship is obtained once $\mathrm{w} / \mathrm{c}$ ratio is replaced by $\mathrm{c} / \mathrm{w}$ ratio. To use the modified DoE plots, it is necessary to obtain the strength of concrete made with water/cement ratio of 0.5 (cement/water ratio of 2 ) using local materials (DoE method). The ACI 211.1 can be directly used for obtaining strength. Moreover, a distinct relationship (similar to that of the ACI 211.1) between w/c ratio and cylinder strength of concrete can be obtained experimentally and used in the mix design procedure instead of using Figure 1 $[10,31]$. Such plots are shown in the comparison of results that will appear later in Figure 5. In Europe, Ujhelyi [32] provided a plot for strength using cements conforming to EN 1971 specifications, composition, specifications, and conformity criteria for common cements (CEM 52.5, 42.5, and 32.5). According to Erdélyi [26] these values are multiplied by 0.92 for EN 206-1 cements. These plots are shown in Figure 1(b) and compared to the values given by the ACI 211.1.

(6) Workability of concrete is classified into three main degrees: low, medium, and high. This includes the most practical workability requirements in most concrete works.

(7) Because workability-cohesion is dependent on amount of cement paste and its cohesiveness all around the fine aggregate particles and inside the packing voids of coarse aggregate, it depends on the total amount of fine aggregates in unit volume of concrete. Hence it can be concluded that the factors WD and WC are interdependent. To account for that, the right hand side of (5) is multiplied by a correction factor $M$. Therefore, a new equation (see (6)) is derived and is written in the form

$$
\text { Adjusted } V_{\mathrm{P}}=M \times \mathrm{WC} \times R_{\mathrm{FA}} \times \frac{W_{\mathrm{FA}}}{D_{\mathrm{FA}}},
$$

where $D_{\mathrm{FA}}$ is the dry loose unit weight of fine aggregates and $W_{\mathrm{FA}}$ is the weight of fine aggregate. A special plot was obtained for the factor $M$, whose details will be explained in the ensuing sections. 


\section{Research Program and Procedure}

The basic steps of the research are

(1) to determine and plot the factors "WC" and "WD" discussed in the previous section taking into account the variables affecting them,

(2) to obtain a distinct relationship between strength of concrete using local materials and the cement/water ratios of cylindrical specimens (similar to that of the ACI 211.1),

(3) to obtain the strength of concrete cubes cast with cement/water ratio of 2 (w/c of 0.5$)$ using local materials (similar to British DoE mix design method).

The procedure that was followed consisted of the following steps.

(I) Various concrete mixes were proportioned and prepared at laboratory conditions using either the ACI 211.1 absolute volume method or the British DoE mix design methods. Then these mixes were carefully adjusted to the required workability and the final mix proportions were obtained.

(II) The factor "WD" was calculated by solving the derived equations (2) and (4) as follows:

$$
\mathrm{WD}=\frac{\mathrm{UV}-A-V_{\mathrm{CA}}}{R \times V_{B_{\mathrm{CA}}}}=\frac{\mathrm{UV}-A-W_{\mathrm{CA}} / G_{\mathrm{CA}}}{R \times W_{\mathrm{CA}} / D_{\mathrm{CA}}},
$$

where $W_{\mathrm{CA}}$ is the adjusted weight of the coarse aggregate used in the mix, $G_{\mathrm{CA}}$ is the specific gravity of the coarse aggregate multiplied by the unit weight of water, and $D_{\mathrm{CA}}$ is the dry loose unit weight of coarse aggregate. UV was taken as 1.0 cubic meter and the unit weight of water was taken as $1000 \mathrm{~kg}$ per cubic meter. All units used are kg-meter units.

In the determination of the "WD" factor, the following variables were taken into consideration: (a) specific gravity of coarse aggregates, (b) the maximum size of aggregates, (c) the fineness of fine aggregates (expressed as fineness modulus), (d) the bulk unit weight and the corresponding voids ratio, and (e) the degree of workability.

(III) During theoretical mix proportioning, the value for the entrapped air voids $(A)$ was first assumed according to the values that appear in the ACI 211.1 mix design method. Later, this value was measured experimentally after final adjustment of the mix proportions.

(IV) The factor "WC" was determined using (2), (4), and (5). Equation (8) can be derived and written in the form

$$
\mathrm{WC}=\frac{M \times V_{\mathrm{P}}}{\left\langle(\mathrm{UV}-A)-\left(V_{\mathrm{P}}+V_{\mathrm{CA}}\right)\right\rangle \times G_{\mathrm{FA}}} \frac{D_{\mathrm{FA}}}{R_{\mathrm{FA}}},
$$

where $G_{\mathrm{FA}}$ is the specific gravity of the fine aggregate multiplied by the unit weight of water and $D_{\mathrm{FA}}$ is the dry loose unit weight of fine aggregates.

The factor "WC" was first calculated (after final mix adjustment) using (8) and entering the corresponding values for $A, V_{\mathrm{P}}$, and $V_{\mathrm{CA}}$. As $V_{\mathrm{CA}}$ depends on the specific gravity of coarse aggregate, the change of specific gravity would result in change of $V_{\mathrm{CA}}$ and thus the correction factor, $M$, was introduced.
(V) In order to obtain the relationship between the "WC" factor and $M$, the factor WC was first found for a constant value of specific gravity $(M$ was assumed $=1.0$ for specific gravity of coarse aggregate $=2.8$, the highest value encountered in the research). The relationship between $M$ and specific gravity was obtained and plotted.

(VI) From steps (IV) and (V), two plots were obtained: one for the factor WC and the other for the factor $M$. The variables that were taken into consideration when factor WC was obtained were (a) the volume of paste which is affected by the degree of workability and the water/cement ratio, (b) the fineness modulus of fine aggregates, (c) the specific gravity, and (d) the loose bulk unit volume of fine aggregate and the corresponding relative voids ratio between aggregate particles.

(VII) Final adjustment of mix proportioning was done for each mix in order to satisfy the desired degree of workability. Air content was measured and then $150 \mathrm{~mm}$ cubes and or $/ 150 \times 300 \mathrm{~mm}$ cylinders were prepared according to the procedures described in the corresponding standards (ASTM and BS). The cubes and cylinders were prepared in groups of 3 or more, cured under standard conditions, and then tested for strength at the age of 28 days.

(VIII) Special mixes of cement/water ratio of 2 were proportioned and then adjusted to the desired degree of workability. $150 \mathrm{~mm}$ cubes were prepared according to the British standards, cured in standard curing conditions, and then were tested for strength at the age of 28 days.

(IX) After all plots were obtained, special mixes were proportioned by the new "cohesion-dispersion" method and compared to the ACI 211.1 and the British DoE mix design methods

(X) The research was conducted in two stages.

Stage 1. This stage started at Kuwait University in 1988. All mixes were prepared under laboratory conditions. Preliminary relationships were obtained using local materials.

Stage 2. This stage was completed in Jordan where the method was applied at site conditions. The sites were at Murhib and Quanta projects for Water Authority where the author worked as a material and quality control engineer. Further tests were also carried out at the labs of Applied Science University and the Hashemite University, where final plots were checked.

\section{Materials}

OPC from two sources was used in all mixes. Kuwaiti OPC was used in Stage 1 and Jordanian OPC was used in Stage 2. Natural and crushed aggregates were introduced in all the mixes. Tables 1 and 2 summarize the properties of the aggregates used. High ranges of grading of aggregates were introduced in the mixes in order to test the applicability of the method for various gradings, which were not, sometimes, accepted by the ACI or the British standards.

\section{Results and Discussion}

5.1. Air Content. Table 3 shows the results of the measurements of entrapped air in concrete. The entrapped air was 
TABLE 1: Properties of coarse aggregate used in the mix.

\begin{tabular}{|c|c|c|c|c|}
\hline Classification & CA1 & CA2 & CA3 & CA4 \\
\hline Local name & Kuwaiti Gravel & Wadi Gravel & Sukhna Coarse Agg. & Yajooz Coarse Agg. \\
\hline Crushed or natural & Natural & Natural & Crushed & Crushed \\
\hline Absorption (\%) & $0.91-1.39$ & $1.03-1.41$ & $1.91-2.23$ & $2.97-4.42$ \\
\hline Specific gravity & $2.57-2.66$ & $2.63-2.79$ & $2.53-2.76$ & $2.49-2.58$ \\
\hline${ }^{* *} \%$ age of samples lying outside ASTM standards (\%) & 12 & 23 & 31 & 37 \\
\hline LA abrasion (\%) & $21-27$ & $20-28$ & $22-32$ & $29-39$ \\
\hline${ }^{* *} \%$ age of samples lying outside BS standards (\%) & 5 & 12 & 22 & 25 \\
\hline
\end{tabular}

** Percentage of samples falling outside the standard limits when tested for grading requirements.

TABLE 2: Properties of fine aggregate used in the mix.

\begin{tabular}{|c|c|c|c|c|}
\hline Classification & FA1 & FA2 & FA3 & FA4 \\
\hline Local name & Desert Sand & Wadi Sand & Suwaileh Sand & Silica Sand \\
\hline Specific gravity & $2.56-2.71$ & $2.63-2.79$ & $2.48-2.60$ & $2.49-2.56$ \\
\hline $\begin{array}{l}{ }^{* *} \% \text { age of samples } \\
\text { lying outside ASTM } \\
\text { grading limits }\end{array}$ & $\begin{array}{l}\text { 15\% (most below } \\
\text { the finer limit) }\end{array}$ & $\begin{array}{l}18 \% \text { (most above } \\
\text { the coarser limit) }\end{array}$ & $\begin{array}{l}65 \% \text { (all below } \\
\text { the finer limit) }\end{array}$ & $\begin{array}{l}80 \% \text { (all below } \\
\text { the finer limit) }\end{array}$ \\
\hline $\begin{array}{l}* * \% \text { age of samples } \\
\text { lying outside BS } \\
\text { grading limits }\end{array}$ & None & $\begin{array}{c}3 \% \text { (all above the } \\
\text { coarser limit) }\end{array}$ & $5 \%$ & $\begin{array}{l}\text { 3\% (all below the } \\
\text { finer limit) }\end{array}$ \\
\hline Fineness modulus & $2.24-2.56$ & $2.46-3.15$ & $1.94-2.28$ & $1.59-2.14$ \\
\hline
\end{tabular}

** Percentage of samples falling outside the standard limits when tested for grading requirements.

TABLE 3: Entrapped air in concrete mixes.

\begin{tabular}{ccccccc}
\hline Stage & Max. aggregate size & Number of tests & Range (min.-max.) & Average & Standard deviation & Deviation from the ACI 211.1 \\
\hline \multirow{2}{*}{ Stage 1 } & 40 & 18 & $0.95-1.35$ & 1.09 & 0.084 & +0.09 \\
& 20 & 42 & $1.75-2.55$ & 2.08 & 0.245 & +0.08 \\
\hline \multirow{2}{*}{ Stage 2 } & 10 & 18 & $2.35-3.50$ & 2.95 & 0.356 & -0.05 \\
& 40 & 28 & $1.00-1.50$ & 1.23 & 0.165 & +0.23 \\
& 20 & 146 & $1.85-2.65$ & 2.20 & 0.283 & +0.20 \\
\hline
\end{tabular}

measured using the pressure method described in the ASTM C231. It is clear that the test results were close to the values shown in the ACI 211.1. Therefore, rounding up the average figures to the nearest integer (for first estimate of mix proportions) leads to values of $1 \%, 2 \%$, and $3 \%$ entrapped air for maximum size of aggregate of 40,20 , and $10 \mathrm{~mm}$, respectively. These values coincide with the assumption that entrapped air values, which appear in the ACI 211.1, are applicable in the mix proportioning.

5.2. Workability. In sites, workability was assessed using practical experience in addition to the slump test results according to the ASTM C143.

In the laboratory, the workability was assessed using the results of the slump, Vebe, and compacting factor tests according to BS 1881, Parts 101, 102, and 103, and also to ASTM C143. Special practical experience in assessing the degree of workability of concrete was also used. No distinct relationships were obtained among results. This was attributed to the high variability of the mixes and the mix proportions. Therefore no plot was presented and results were not shown. Dewar 1964 showed high variations in results along with varying aggregate/cement ratios. Although some authors showed good correlation between compacting factor or Vebe and workability $[9,10,13,14]$, these tests are not usually used at sites and hence remain as laboratory control tests. However, the tables that appear in the references can be used as guidelines to assess the degree of workability of the tested concrete but cannot replace practical experience.

5.3. The Workability-Dispersion Factor "WD”. Figure 2 shows the relationship between the fineness modulus of sand and the "WD" factor multiplied by the factor $Z$, for normalization of results. It was found that, for the same size of aggregate, the "WD" increases by the increase in fineness modulus or 


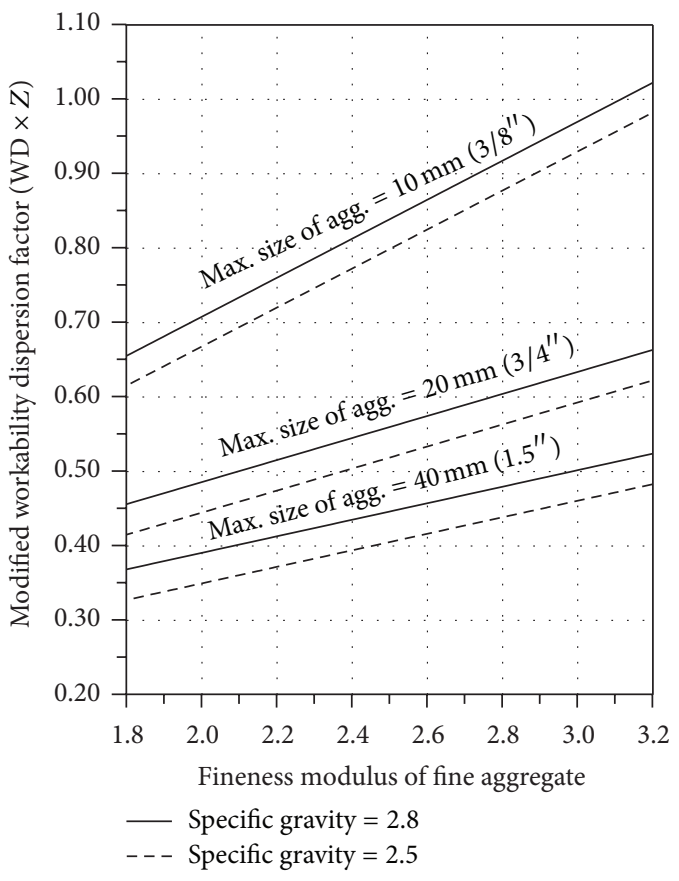

FIGURE 2: Relationship between fineness modulus of fine aggregate and the workability-dispersion factor.

the increase in the specific gravity of aggregate. However it was observed, practically, that the change in the degree of workability from low to high resulted in minor changes in the value of the "WD" factor. The difference ranged from plus $4 \%$ to minus $3 \%$. Therefore, it was concluded that, for practical acceptable degree of workability for normal works, the major factors affecting the amount of coarse aggregate in the mix are the fineness of sand and the maximum size of aggregate. These conclusions and observations coincide with the table presented by the ACI 211.1.

The relationships between the "WD" factor and the fineness modulus of fine aggregate were found to be linear for the same specific gravity ( $R^{2}$ ranged from 0.9665 to 0.9931$)$.

5.4. The Workability-Cohesion Factor. Figure 3 shows the relationship between the workability-cohesion factor "WC," multiplied by the $Z^{\prime}$ factor, and the fineness modulus of fine aggregates for different $c / w$ ratios and various degrees of workability. It is clear from the plot that for the same degree of workability the "WC" factor decreases by the increase in the fineness modulus or decrease in the $\mathrm{c} / \mathrm{w}$ ratio. Also, for the same fineness modulus and the same $c / w$ ratio, the factor "WC" increases by the increase in the workability of concrete. This can be attributed to the higher volume of paste required for the higher degree of workability [15]. The values that appear in the plot are for constant specific gravity of coarse aggregate. For simplicity, the values of the "WC" were plotted for a specific gravity of 2.8 (the highest value used in the research). For other values of specific gravity, a correction factor $(M)$ is obtained by using the plot for $M$. It is clear from Figure 4 that the correction factor $(M)$ increases by the decrease in the specific gravity. A linear relationship was obtained between the specific gravity " $G$ " and the factor " $M$ " in the form of $M=2.548-0.554 G$ with $R^{2}=0.996$.

\subsection{Strength}

5.5.1. Stage 1. Since the DoE mix design method is based on the strength of $150 \mathrm{~mm}$ cubes made with $\mathrm{w} / \mathrm{c}$ ratio of 0.50 , the strength of cubes made with OPC of Kuwait and with cement/water ratio of 2 was measured and found to be $39.6 \mathrm{MPa}$ at the age of 28 days. The standard deviation was $2.43 \mathrm{MPa}$ and the range for the $5 \%$ defects was 42.04 to 37.18 $\mathrm{MPa}$. The minimum value was 35 and the maximum was $44 \mathrm{MPa}$. The use of cubes rather than cylinders for the DoE mix design method is necessary to get better comparisons. For mixes designed according to ACI, $150 \times 300 \mathrm{~mm}$ cylinders were prepared and tested. Wherever comparisons of the cube and cylinder strength are necessary, the cylinder strength is assumed as 0.80 that of the cube strength [15]. Such value is recommended in Jordanian and Kuwaiti specifications.

The relationship between the cement/water ratio and the strength of concrete is shown in Figure 5. The relationship was linear in a pattern similar to that shown in Figure 1. The values of the ACI 211.1 are plotted for comparison. It is seen that, for $\mathrm{c} / \mathrm{w}$ ratio of 1.8 and above, the ACI values tend to be higher than those of the author's. The ACI values are close to the values obtained by the author for the lower $\mathrm{c} / \mathrm{w}$ ratios. Therefore, it can be concluded that the use of the ACI 211.1 method would result in lower strength values than expected for mixes with somewhat high $\mathrm{c} / \mathrm{w}$ ratio. Hence, it can be concluded that slightly lower $\mathrm{w} / \mathrm{c}$ ratio is required to attain the same strength results if the ACI method is used in the design. The author suggests a value of 0.02 . The author findings here are comparable to those of El-Rayyes, 1982, under the same conditions. All plots between $\mathrm{c} / \mathrm{w}$ ratio and strength are linear ones as shown in Figure 5.

5.5.2. Stage 2. Repeating the same procedure as in Stage 1, the strength of cubes made with $\mathrm{c} / \mathrm{w}$ ratio of 2 and tested at 28 days using OPC of Jordan was found to be $41.8 \mathrm{MPa}$ with a standard deviation of $5.09 \mathrm{MPa}$. The $5 \%$ defects ranged from 33.45 to $50.15 \mathrm{MPa}$. The strength of concrete samples versus $\mathrm{c} / \mathrm{w}$ ratios is shown in Figure 5. The results are compared to those of the ACI 211.1 and a modified replot of those of Abdul-Jawad, 1984, using c/w ratios instead of the traditional $\mathrm{w} / \mathrm{c}$ ratios. It is clear from the plots that values obtained by Abdul-Jawed are the highest. This can be attributed to the fact that Abdul-Jawad used selective materials under laboratory conditions while the author presented practical data obtained under various site conditions using available materials. Also, the author's values are somewhat below the values of the ACI 211.1. Furthermore, the relationship between $\mathrm{c} / \mathrm{w}$ ratio and strength was found to be linear for all plots.

\section{Steps of Mix Design}

The following are the main design steps that must be followed in the design of normal concrete mixes by the "cohesiondispersion" method discussed in these articles. 

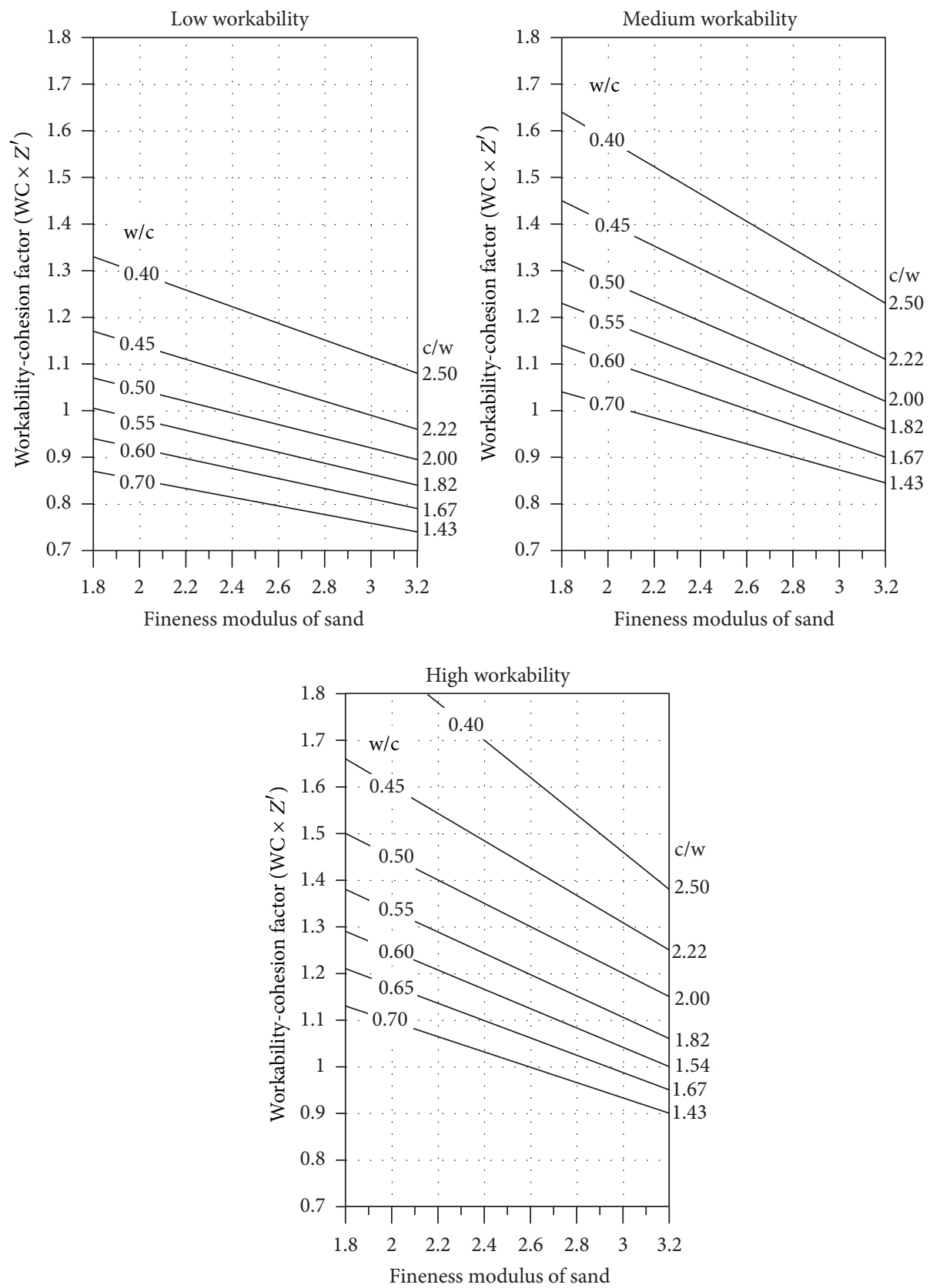

FIGURE 3: Relationship between fineness modulus, cement water ratio (w/c ratio), and workability-cohesion factor.

Step 0 (identify and classify the aggregates to be used in the mix). The properties of aggregates should be studied and well understood before designing the concrete mix. The following tests must be done:

(1) Sieve analysis.

(2) Unit weight and voids ratio in aggregates.

(3) Specific gravity and absorption.

The following variables must be obtained or estimated:

(1) The grading of aggregates and deviation from the standards if any deviation is present in the results.
(2) The maximum size of aggregates.

(3) The fineness modulus of fine aggregate.

(4) The specific gravity and absorption of all ingredients that will be used in the mix.

(5) The dry loose unit weight of both fine and coarse aggregates.

(6) The voids ratio in dry loose aggregates which is calculated using the relationship [15]:

Voids Ratio

$$
=1-\frac{\text { Bulk Dry Loose Unit Weight }}{\text { Specific Gravity } \times \text { Unit Weight of Water }} .
$$




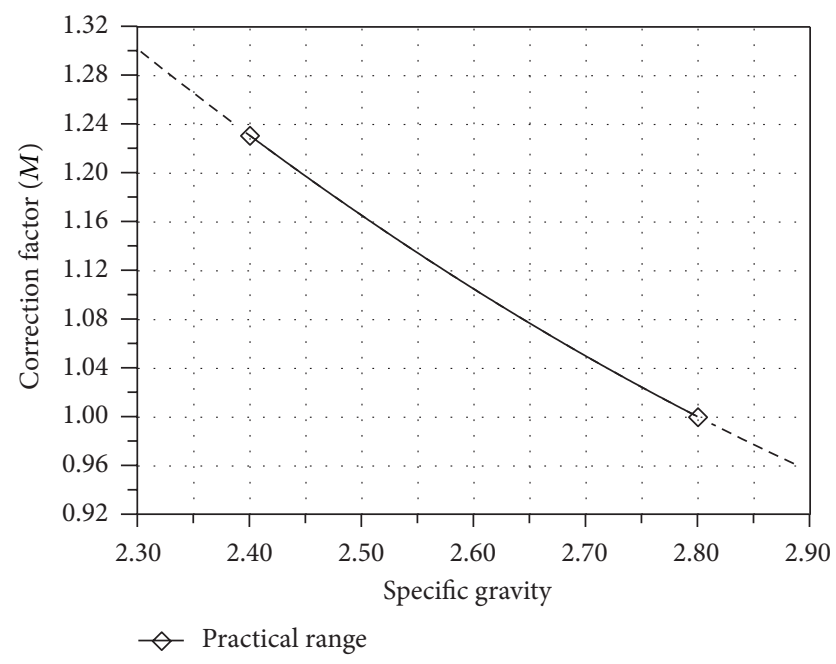

FIGURE 4: Relationship between specific gravity of coarse aggregate and the correction factor $(M)$.

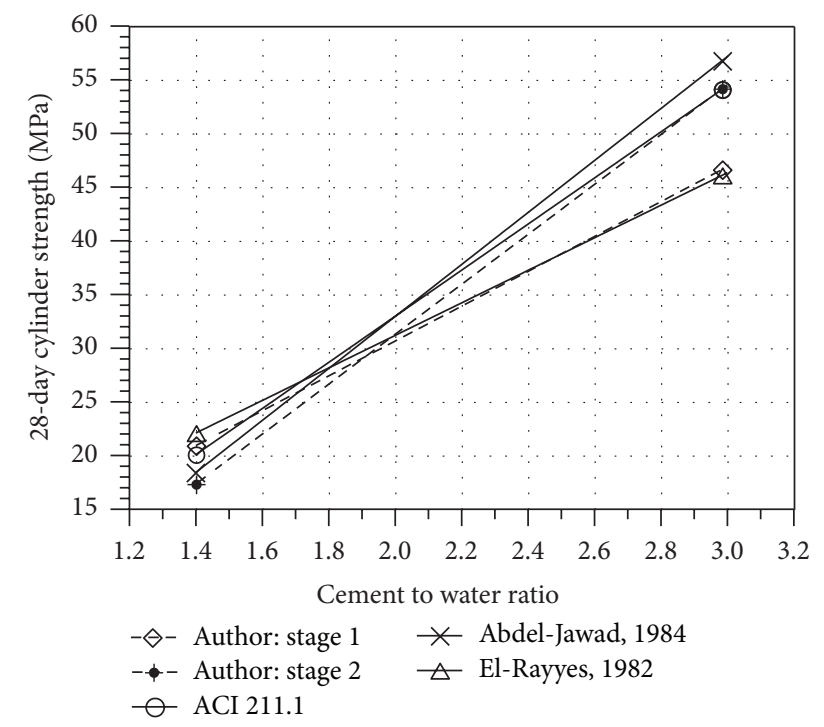

FIGURE 5: Comparison of the relationship between $\mathrm{c} / \mathrm{w}$ ratio and strength of concrete in $\mathrm{MPa}$.

Step 1 (choose the target design strength). The target design strength is chosen using the normal procedure:

$$
\begin{aligned}
\text { Target Strength }= & \text { Specified Strength } \\
& + \text { Standard Deviation } \\
& \times \text { Probability Factor. }
\end{aligned}
$$

Step 2 (choose target cement/water ratio). The cement/water ratio is chosen so that it satisfies strength, durability, or impermeability. Figures 1 and 5 can be used for the estimation of the cement/water ratio to satisfy strength requirements. Cement/water ratio required satisfying durability requirements could be obtained by using any recognized specifications such as those of the ACI or BS.
Step 3 (choose workability). If workability is not specified, use local specifications to estimate the required degree of workability. Use of the tables that appear in the literature such as those of the in the ACI 211.1 and the British DoE methods of mix designs is beneficial for less-experienced individuals.

Step 4 (estimate the "WD" factor). The "WD" factor is obtained using Figure 2. From the figure, the factor $\mathrm{WD} \times Z$ is obtained. The factor "WD" then equals the value obtained from the figure divided by $Z$, where

$$
=\frac{\text { Dry Bulk Loose Unit Weight of Coarse Aggregate }}{\text { Voids Ratioin Coarse Aggregate }} .
$$

Step 5 (calculate the coarse aggregate content). The weight of coarse aggregates is calculated using the relationship

$$
W_{\mathrm{CA}}=\frac{1-A}{1 / G_{\mathrm{CA}}+{ }^{\text {"WD" }} \times Z} \text {. }
$$

The value of $A$ can be assumed 1\%, 2\%, and 3\% for maximum size of aggregate of 40,20 , and $10 \mathrm{~mm} . G_{\mathrm{CA}}$ is the specific gravity of coarse aggregates.

Step 6 (estimate the "WC" factor). The "WC" factor is estimated using Figure 4. The cement/water ratio is obtained from Step 2 while the degree of workability is obtained from Step 3. The value obtained from Figure 3 is then divided by the value $Z^{\prime}$ to obtain the value of the "WC" factor, where

$$
\begin{aligned}
& Z^{\prime} \\
& \text { Dry Bulk Loose Unit Weight Of F. A. } \\
& =\overline{\text { Specific Gravity Of F. A. } \times \text { Voids Ratio In F. A. }} \text {. }
\end{aligned}
$$

Step 7 (estimate correction factor " $M$ ”). The correction factor is obtained from Figure 4.

Step 8 (calculate the weight of fine aggregate). The weight of fine aggregate is calculated using the formula

$$
W_{\mathrm{FA}}=\frac{(\mathrm{WD} \times Z) \times W_{\mathrm{CA}}}{1 / G_{\mathrm{FA}}+M \times(\mathrm{WC})\left(R_{\mathrm{FA}} / D_{\mathrm{FA}}\right)} .
$$

The values of $W_{\mathrm{CA}}, W_{\mathrm{FA}}$, and $M$ are obtained from Steps 5,6 , and 7 , respectively. $G_{\mathrm{FA}}$ is the specific gravity of fine aggregates. The factor $Z^{\prime}$ is calculated using the following relationship.

Step 9 (calculate the volume of the paste). The volume of the paste is calculated using (6).

Step 10 (calculate the cement and water contents). Cement and water contents are calculated using the relationships

$$
V_{\mathrm{P}}=V_{\mathrm{W}}+V_{\mathrm{C}}=\frac{\mathrm{w} / \mathrm{c} \times W_{\mathrm{C}}}{\text { Water Density }}+\frac{W_{\mathrm{C}}}{\text { Cement Density }}
$$


TABLE 4: The results of 220 mixes obtained during the 24 years of study.

\begin{tabular}{|c|c|c|c|c|}
\hline Variable $^{\mathrm{a}}$ & The final mean value ${ }^{\mathrm{b}}(\%)$ & 95\% significant interval & Coefficient of variation (\%) & Notes \\
\hline $\mathrm{c} / \mathrm{w}$ ratio & 98 & 90-103 & 6 & $\begin{array}{l}\text { Slightly lower than } \\
\text { estimated }^{\mathrm{c}}\end{array}$ \\
\hline Water content & 104 & $92-111$ & 11 & $\begin{array}{l}\text { Slightly higher than } \\
\text { estimated }\end{array}$ \\
\hline Cement content & 103 & 95-108 & 7 & $\begin{array}{l}\text { Interdependent on the } \\
\text { previous two variables }\end{array}$ \\
\hline CA content & 104 & $94-113$ & 10 & $\begin{array}{l}\text { Slightly higher than } \\
\text { estimated }\end{array}$ \\
\hline FA content & 95 & $88-103$ & 8 & $\begin{array}{l}\text { Slightly higher than } \\
\text { estimated }\end{array}$ \\
\hline
\end{tabular}

a: the value is assumed $100 \%$.

$\mathrm{b}$ : the value after mix adjustment for practical use.

c: $w / c$ ratio is higher.

Then

$$
V_{\mathrm{P}}=W_{\mathrm{C}}\left(\frac{\mathrm{w} / \mathrm{c}}{\text { Water Density }}+\frac{1}{\text { Cement Density }}\right) .
$$

And, $\mathrm{w} / \mathrm{c}=W_{\mathrm{W}} / W_{\mathrm{C}}$.

Note that $V_{\mathrm{P}}$ is obtained from Step 9 and w/c ratio from Step 2. The specific gravity of cement can be assumed 3.14 or 3.15 if not known.

Step 11 (modify and adjust initial mix proportions). The values obtained from the previous steps should be modified if any limitations (e.g., limitations on cement content) are specified. When values are modified, the cement/water ratio should be kept constant and the other values should be modified so that the unit volume principle is kept applicable.

Step 12 (test and adjust the final mix). Trial mixes should be made and tested for the required properties. Any adjustments should be made. The mix can be adjusted for stability, if segregation is observed, by choosing a lower value of WD or a higher value of WC. The opposite can be done if sticky mixes are observed. However, the rule of thumb described in the ACI 211.1 is quite helpful in adjusting the mix proportions.

\section{Repeatability and Reproducibility of Results}

The final values of the mixture proportions have been tested for repeatability and reproducibility for the mixes. All results showed that the values obtained are significant and statistically accepted. In order to minimize the huge number of calculations and to simplify things for the reader, final results are given in Table 4 . In this table, the $\mathrm{c} / \mathrm{w}$ ratio, the water content, the cement content, and the fine and coarse aggregate contents which are obtained using the method are assumed as $100 \%$. The results of 220 mixes obtained during the 24 years of study are given in Table 4 .

Statistical analysis of all the plots that appear in Figures 26 shows that $R^{2}$ is above 0.90 and the $95 \%$ confidence interval is within acceptable limits. Because of the huge number of plots, the results are not shown on the plots to avoid congestion of points that lead to misreading.

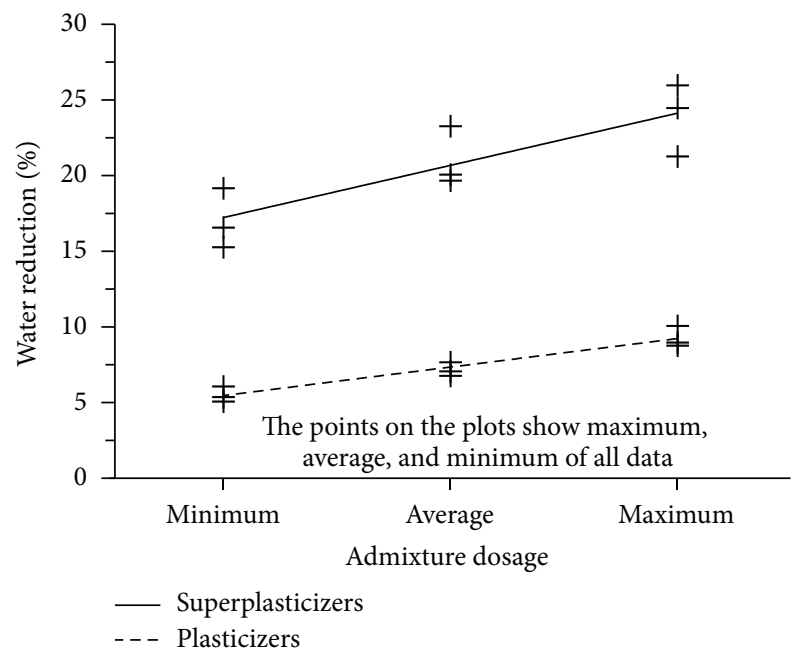

Figure 6: Water reduction when admixtures are used.

\section{Effect of Water Reducing Admixtures}

The use of plasticizers, water reducers, superplasticizers, and high-range water reducers will reduce the amount of water while maintaining the workability. In general, plasticizing and water reducing admixtures can reduce water content by 5 to $10 \%$, while superplasticizing and high-range water reducing admixtures can reduce water content between 15 and $30 \%$ (ACI 212.3R). The reduction depends on the type of admixture, the dosage, and the workability of concrete.

In order to study the effect of admixtures on the water reduction in concrete, several mixes have been prepared and tested in the lab. Eleven commercially used types of plasticizers and other seven of superplasticizers have been used in the mixes. Figure 6 shows the water reduction in concrete mixes when the admixtures are incorporated. All the results are within the expected limits reported in the ACI 212.3R.

\section{Durability Requirements}

ACI 211.1 requirements to attain durability against sulfate attack and seawater can be safely used. The correct choice of 
$\mathrm{w} / \mathrm{c}$ ratio and the type of cement would result in safe durable concrete. Also, the engineer can follow the requirements of BS 8110 .

\section{Summary and Conclusions}

The workability-dispersion-cohesion method of concrete mix design presented here would be a better choice for regions where local materials might not follow certain specifications allowing the use of wide ranges of aggregate gradation and properties.

The first factor (workability-dispersion) represents the mobility and easiness of concrete production, including its compactability, while the second factor (workability-cohesion) represents the stability, cohesion, and homogeneity, of the concrete mix. The method proposed here ensures a mobile and stable concrete mix design.

The use of the $\mathrm{c} / \mathrm{w}$ ratio instead of the traditional $\mathrm{w} / \mathrm{c}$ ratio would be easier in estimating the proportions required for mix design because of the easier linear interpolations. It is clear that all the relations presented in the plots are linear relationships, which make the use of the method easy and simply programmable. Because of the presence of the workability-cohesion and workability-dispersion factors, the workability-cohesion-dispersion method can be extended to include various concrete mixes such as concrete-containing admixtures and self-compacting concrete.

\section{On-Going Research}

The work presented in this paper is the first stage of an extensive research that covers various types of concrete. The author is investigating the application of the method when various types of admixtures are introduced. They will be published in the future once they are statistically tested and approved.

Furthermore, the application of the method for special types of concrete, such as self-compacting concrete, is under investigation.

\section{Appendix}

\section{Example}

Assume that the strength requirements for a medium workability mix ended with a $\mathrm{c} / \mathrm{w}$ ratio of $1.67(\mathrm{w} / \mathrm{c}=0.6)$ and that the specific gravity of coarse and fine aggregate is 2.65 and 2.60, respectively. The coarse aggregate has a max. size of $20 \mathrm{~mm}$. The loose unit weights of coarse and fine aggregates are 1.45 and 1.4 tons/cubic meter, respectively. Fineness modulus of sand $=2.20$. Consider

$$
R=1-\frac{1.45}{2.65}=0.453 \text {. }
$$

From Figure 2 using the specific gravity of coarse aggregates and the fineness modulus of sand then WD $\times Z=0.495$; hence $\mathrm{WD}=0.495 \times 1.45 / 0.453=1.58$.

Assume $A=2 \%$ for max. size of $20 \mathrm{~mm}$. Then

$$
W_{\mathrm{CA}}=\frac{(1-0.02) \times 1000}{(1 / 2.65)+0.495}=1123 \mathrm{~kg} \text {. }
$$

From Figure 4 using c/w value, medium workability plot, and fineness modulus of 2.20 , the $\mathrm{WC} \times Z^{\prime}$ will be 1.12 . Also the $R_{\mathrm{FA}}$ value $=1-1.40 / 2.60=0.462$. Also from Figure 3, the $M$ value is 1.076 . Then $\mathrm{WC}=(1.12 \times 1.40 / 2.60 \times 0.462) \times 1.076=$ 1.404 .

The weight of fine aggregate is then calculated as follows:

$$
\begin{aligned}
W_{\mathrm{FA}} & =\frac{0.495 \times 1123}{(1 / 2.6)+1.404 \times 0.462 / 1.40} \times 1000 \\
& =656 \mathrm{~kg} .
\end{aligned}
$$

Once the weight of fine aggregate is estimated, the volume of paste is calculated as $V_{\mathrm{P}}=1.404 \times 0.462 \times 656 / 1400=$ 0.304 cubic meter, which equals $V_{\mathrm{C}}+V_{\mathrm{W}}$. Then $0.304=$ $(1 / 1000)\left(W_{\mathrm{C}} / 3.15+\left(\mathrm{w} / \mathrm{c} \times W_{\mathrm{C}}\right) / 1.0\right)$, from which $W_{\mathrm{C}}$ is $332 \mathrm{~kg}$. And $W_{\mathrm{W}}$ is $199 \mathrm{~kg}$.

Therefore the weights required are $332 \mathrm{~kg}$ of cement, $199 \mathrm{~kg}$ of water, $1123 \mathrm{~kg}$ of coarse aggregates, and $656 \mathrm{~kg}$ of sand.

\section{Notations}

A: $\quad$ Volume of air voids in concrete

$B_{1}$ : $\quad$ Factor relating the bulk volume of mortar to the solid volumes of mortar particles

$B_{2}$ : $\quad$ Factor allowing for the dispersion of coarse aggregate particles

$B_{\mathrm{FA} 1}$ : Factor relating the bulk volume of paste to the solid volumes of paste particles

$B_{\mathrm{FA} 2}$ : Factor allowing for the cohesion of fine aggregate particles

$D_{\mathrm{CA}}$ : Dry loose unit weight of coarse aggregates

$D_{\mathrm{FA}}$ : Dry loose unit weight of fine aggregates

DoE: Department of Environment

$G_{\mathrm{CA}}$ : Specific gravity of coarse aggregate $\times$ unit weight of water

$G_{\mathrm{FA}}$ : Specific gravity of fine aggregates $\times$ unit weight of water

M: $\quad$ Correction factor

$R: \quad$ Voids ratio in loose coarse aggregate

$R_{\mathrm{FA}}$ : Voids ratio in loose fine aggregate

$V_{B_{\mathrm{CA}}}: \quad$ Bulk volume of dry loose coarse aggregate

$V_{B_{\mathrm{FA}}}: \quad$ Bulk volume of dry loose fine aggregate

$V_{\mathrm{C}}: \quad$ Volume of cement

$V_{\mathrm{CA}}$ : Volume of coarse aggregate

$V_{\mathrm{CO}}$ : Volume of concrete in its final stage

$V_{\mathrm{M}}$ : Volume of mortar

$V_{\mathrm{P}}$ : $\quad$ Volume of paste

$V_{\mathrm{S}}: \quad$ Volume of sand

$V_{\mathrm{W}}$ : Volume of water

WC: Workability-cohesion factor

WD: Workability-dispersion factor

$W_{\mathrm{FA}}$ : Weight of fine aggregate

$W_{\mathrm{CA}}$ : Weight of coarse aggregate

$Z \& Z^{\prime}$ : Chart factors.

\section{Competing Interests}

The author declares that they have no competing interests. 


\section{References}

[1] D. A. Abrams, Design of Concrete Mixtures, Structural Materials Research Laboratory, Lewis Institute, Chicago, Ill, USA, Bulletin no. $1,1918$.

[2] Road Research Laboratory, "Design of concrete mixes," Road Note 4, HMSO, London, UK, 1950.

[3] B. P. Hughes, "The rational design of high quality concrete mixes," Concrete, vol. 2, no. 5, pp. 212-222, 1968.

[4] B. P. Hughes, "The economic utilization of concrete materials," in Proceedings of the Symposium on Advances in Concrete, Concrete Society, London, UK, 1971.

[5] G. R. Krishnamurti, "A new economic method of concrete mix design," Cement and Concrete, vol. 13, no. 2, pp. 160-171, 1972.

[6] B. W. Shacklock, Concrete Constituents and Mix Proportions, Cement and Concrete Association, London, UK, 1974.

[7] A. Komar, Building Materials and Components, Mir Publishers, Moscow, Russia, 1974.

[8] D. C. Teychenne, R. E. Franklin, and H. Erntroy, Design of Normal Concrete Mixes, Department of Environment, H.M.S.O., London, UK, 1975.

[9] D. C. Teychenne, J. C. Nicholls, R. E. Franklin, and D. W. Hobbs, Design of Normal Concrete Mixes, Building Research Establishment, Department of Environment, HMSO, London, UK, 1988.

[10] M. El-Rayyes, "A simple method for the design of concrete mixes in the Arabian gulf," Journal of the University of Kuwait (Science), vol. 9, no. 2, pp. 197-208, 1982.

[11] A. F. Abbasi, M. Ahmad, and M. Wasim, "Optimization of concrete mix proportioning using reduced factorial experimental technique," ACI Materials Journal, vol. 84, no. 1, pp. 55-63, 1987.

[12] N. Krishna Raju, Design of Concrete Mixes, CBS Publishers and Distributers, New Delhi, India, 1993.

[13] ACI Committee 211.1, Standard Practice for Selecting Proportions of Normal, Heavyweight, and Mass Concrete, part 1, ACI Manual of Concrete Practice, 2014.

[14] A. M. Neville, Properties of Concrete, Pitman Publishing Company, London, UK, 3rd edition, 1996.

[15] A. M. Neville and J. J. Brooks, Concrete Technology, Longman, London, UK, 2012.

[16] Kuwaiti Specification Committee, General Specifications for Building and Engineering Works, 1st edition, 1990 (Arabic).

[17] Jordanian Specification Committee, Ministry of Public Works, and Housing, General Specifications for Buildings: Volume 1: Civil and Architectural Works, Ministry of Public Works and Housing, Amman, Jordan, 1st edition, 1985 (Arabic).

[18] Saudi Specification Committee and Ministry of Public Works and Housing Saudi Arabia, General Specifications for Building Execution, 1st edition, 1982 (Arabic).

[19] L. J. Murdock and K. M. Brook, Concrete Materials and Practice, Edward Arnold, London, UK, 1979.

[20] F. M. S. Amin, S. Ahmad, and Z. Wadud, "Effect of ACI concrete mix design parameters on mix proportion and strength," in Proceedings of the Civil and Environmental Engineering Conference: New Frontiers and Challenges, pp. III-97-III-106, Bangkok, Thailand, November 1999.

[21] Z. Wadud, A. F. M. S. Amin, and S. Ahmad, "Voids in coarse aggregates: an important factor overlooked in the ACI method of normal concrete mix design," in Proceedings of the International Structural Engineering and Construction Conference (ISEC '01), pp. 423-428, Honolulu, Hawaii, USA, January 2001.
[22] Z. Wadud and S. Ahmad, "ACI method of concrete mix design: a parametric study," in Proceedings of the Eighth East Asia-Pacific Conference on Structural Engineering and Construction, Paper no. 1408, Nanyang Technological University, Singapore, 2001.

[23] M. C. Nataraja and L. Das, "Concrete mix proportioning as per is 10262:2009-comparison with is 10262:1982 and ACI 211.1-91," Indian Concrete Journal, vol. 84, no. 9, pp. 64-70, 2010.

[24] S. C. Maiti, R. K. Agarwal, and R. Kumar, "Concrete mix proportioning," The Indian Concrete Journal, vol. 80, no. 12, pp. $23-$ $26,2006$.

[25] S. Ahmad, "Optimum concrete mixture design using locally available ingredients," The Arabian Journal for Science and Engineering, vol. 32, no. 1, pp. 27-33, 2007.

[26] A. Erdélyi and S. Fehérvári, "Guide for mix design for concrete," Report for Civil Engineering, Department of Construction Materials and Engineering Geology Budapest University of Technology and Economics, 2006.

[27] ODA, "Designing concrete mixes using local materials," Tech. Rep. 6990/05A, Overseas Development Administration (ODA), Gifford and Partners, London, UK, 1997.

[28] K. Newman, "Properties of concrete," Structural Concrete, vol. 2, no. 11, pp. 451-482, 1965.

[29] F. K. Kong and R. H. Evans, Reinforced and Prestressed Concrete, VNR, London, UK, 1983.

[30] J. D. Dewar, "Relations between various workability control tests for ready mixed concrete," Tech. Rep. TRA/375, Cement and Concrete Research Association, London, UK, 1964.

[31] Y. Abdel-Jawad, Optimal design criteria for concrete mixes in Irbid [M.S. thesis], Yarmouk University, 1984.

[32] J. Ujhelyi, Betonismeretek (Concrete Science), BME Editing House, Budapest, Hungry, 2005. 


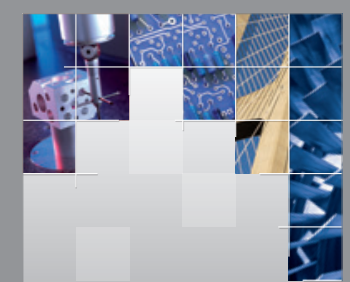

\section{Enfincering}
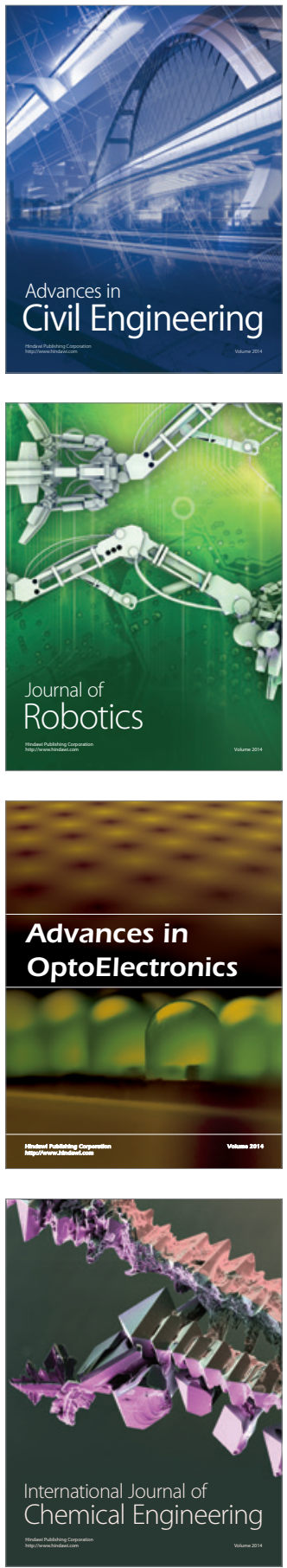

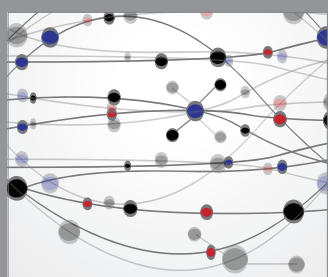

The Scientific World Journal

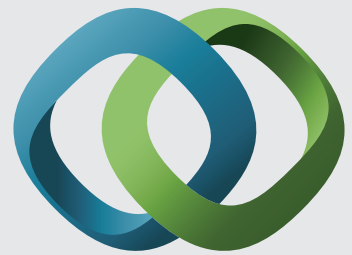

\section{Hindawi}

Submit your manuscripts at

http://www.hindawi.com
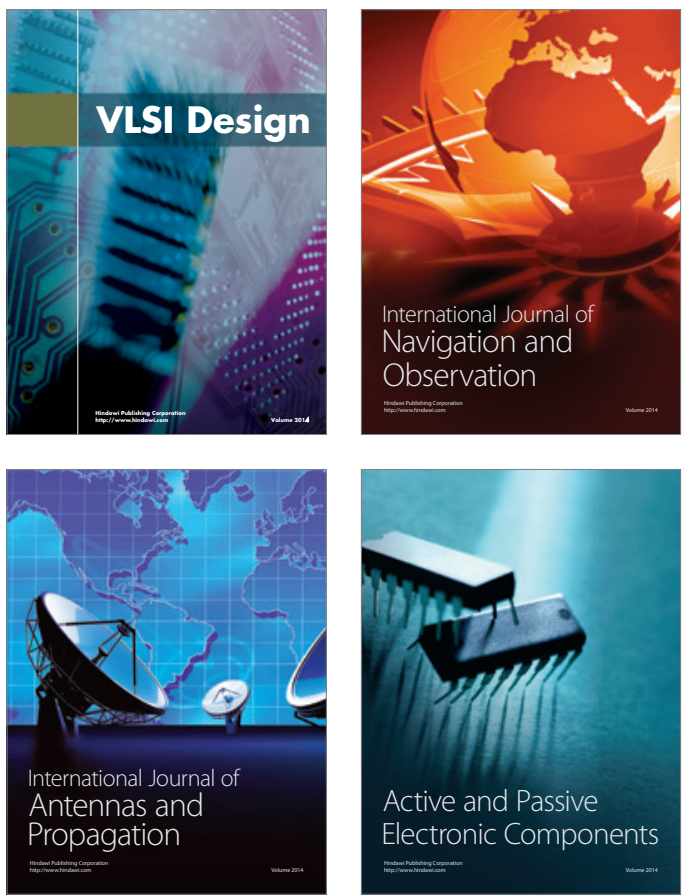
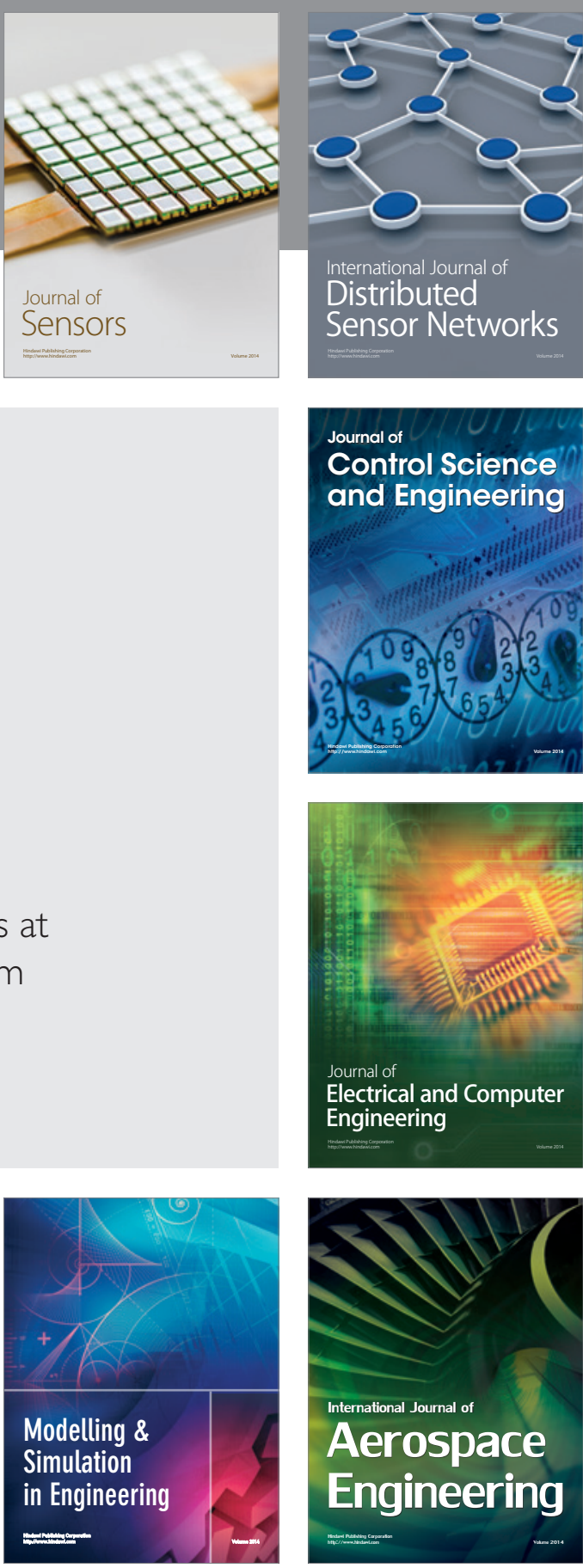

International Journal of

Distributed

Sensor Networks

Journal of

Control Science

and Engineering
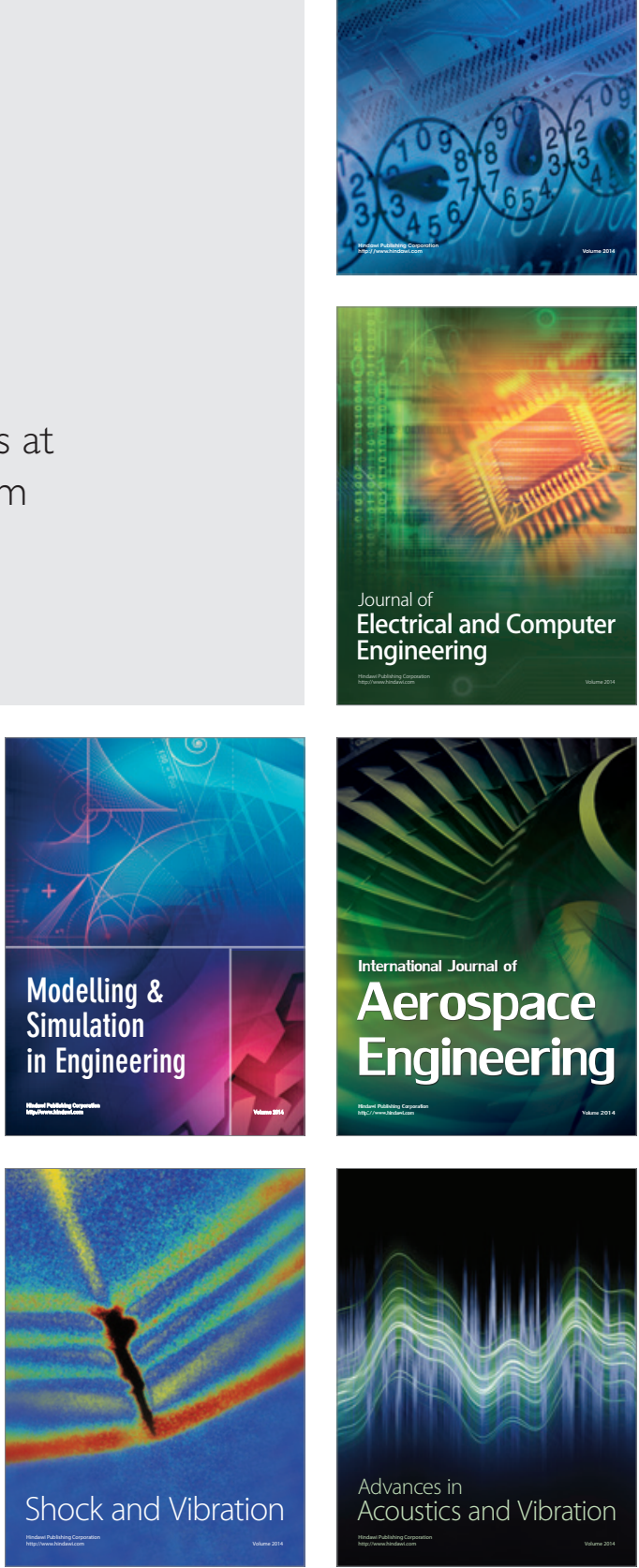